\title{
A documentação do Conselho Ultramarino como património arquivístico comum: subsídios à sua história ${ }^{1}$
} The Records of the Conselho Ultramarino as a Common Archival Heritage: A Contribution to their History

Ana Canas Delgado Martins *,**

\section{Resumo}

Ao estudar aspetos da trajetória dos arquivos do Conselho Ultramarino e da Secretaria de Estado da Marinha e dos Domínios Ultramarinos, órgãos da administração colonial portuguesa central e os reflexos no uso da documentação, este artigo analisa a organização atual desses arquivos e chama a atenção para precauções metodológicas essenciais na recuperação de informação. Ao abordar as raízes da constituição das séries geográficas por meio da pesquisa histórica, utiliza-se como exemplo a série da capitania de São Paulo e sublinha-se a variabilidade das configurações administrativas do Brasil colonial. Com o conhecimento adquirido através do estudo desses arquivos enquanto objeto, apontamos para o imperativo do relacionamento entre documentos de vá-

\section{Abstract}

Through a study of aspects of the historical trajectory of the archives of the Conselho Ultramarino (Overseas Council) and the Secretaria de Estado da Marinha e dos Domínios Ultramarinos (State Department of Naval Affairs and Overseas Domains), institutions of the central Portuguese colonial administration and the reflexes of this history in the use of the documentation, this article analyses the present-day arrangement of these archives. It also highlights the need to take basic methodological precautions when recovering information present in archives. In exploring the roots of the constitution of the "geographical series" by means of historical research, the author takes as an example the archival series of the Captaincy of São Paulo and emphasizes the variability in the administrative configurations

\footnotetext{
* Universidade de Lisboa, Centro de História. Lisboa, Portugal.

** Arquivo Histórico Ultramarino. Lisboa, Portugal. canasdelgadom@sapo.pt <https://orcid.org/00000003-0566-0836>
} 
rias séries de modo a obter uma visão mais próxima do que terá acontecido no passado.

Palavras-chave: Conselho Ultramarino; história dos arquivos; arquivos coloniais. of Colonial Brazil. Informed by the examination of these archives, the article stresses the need to understand the relations existing between documents from various series in order to obtain a clearer insight into events of the past.

Keyword: Overseas Council; history of archives; colonial archives.

\section{1}

Uma parte dos arquivos relativos ao Brasil que se conservaram até hoje tem como parceiro Portugal e outros países e comunidades que, num quadro colonial, eram administrados pelos mesmos organismos sediados em Lisboa, numa ótica de conjunto, mas atendendo à informação variável transmitida a partir das entidades administrativas e de governo nas colónias. O Conselho Ultramarino, desde 1642-1643, e a Secretaria de Estado dos Negócios da Marinha e dos Domínios Ultramarinos, desde 1736 e sobretudo desde meados do século XVIII, constituíram os eixos da administração colonial portuguesa central no que respeita ao Brasil. Assim sucedeu até à inversão, em 1808, do estatuto colonial deste território, derivada da transferência da família real e do governo para o Rio de Janeiro, a fim de salvaguardar a independência política de Portugal.

O essencial dos arquivos de ambos os organismos forma a estrutura do que se convencionou designar fundo de arquivo "do Conselho Ultramarino" no Arquivo Histórico Ultramarino (AHU) em Lisboa.

O Conselho Ultramarino funcionou até 1833, com alterações relevantes já a partir de meados do século XVIII e mais profundas entre 1808 e 1821, período em que a sua atividade perdeu expressão política.

A Secretaria de Estado dos Negócios da Marinha e Conquistas ou Domínios Ultramarinos, criada em 1736 a par de duas novas secretarias de Estado, a dos Negócios Estrangeiros e da Guerra e a dos Negócios do Reino, sofreu diversas reorganizações durante o período da Monarquia Constitucional portuguesa a seguir à Revolução de 1820 e após a independência do Brasil. Referem-se em particular a redução à Marinha e a redistribuição dos assuntos ultramarinos por outras secretarias de Estado por breves períodos em 1821 e em 1834. 
Em 1835, os negócios da Marinha e do Ultramar passaram novamente a ser governados por uma mesma Secretaria de Estado, e os arquivos que produziu até 1910-1911 constituem no AHU um fundo diferente daquele do Conselho Ultramarino.

Uma terceira proveniência arquivística neste fundo, menos significativa, é composta por alguma documentação do Conselho da Fazenda (criação filipina, de 1591), transferida para o Conselho Ultramarino, a fim de apoiar o desempenho de algumas funções financeiras que este herdou do primeiro.

Outras proveniências podem ser ainda assinaladas no fundo do Conselho Ultramarino, sobretudo quanto a documentação derivada da acumulação ou sucessão de cargos por titulares de pastas governativas, como terá sido o caso de documentos criados no âmbito das funções exercidas por D. Diogo Mendonça Corte Real, secretário de Estado do rei D. João V entre 1707 e 1736. Corte Real, além dos assuntos diplomáticos, teve a seu cargo a Secretaria das Mercês, do Expediente e da Assinatura, os negócios da Mordomia-mor, e o despacho dos cargos de monteiro-mor e provedor das obras do Paço (Miranda, 2009).

Finalmente, esse fundo integra parte de arquivos criados em colónias portuguesas e pontualmente recolhidos a Lisboa, como aconteceu com a documentação dos governos-gerais de Angola e Moçambique entre 1891 e 1896, por iniciativa de António Enes (Fitzler, 1928, Introd. de Ernesto Enes e p.133) sobretudo por razões de conservação. Os documentos avulsos assim transferidos acabaram por ser incluídos, entre o final da década de 1970 e a seguinte, nas respetivas séries geográficas do fundo de arquivo do Conselho Ultramarino. ${ }^{2}$ Esta opção obriga a um maior cuidado para os contextualizar e descrever corretamente. Algumas caraterísticas externas distintas destes documentos, como o tipo de papel e a sua dimensão, ajudam a destrinçar os arquivos de que faziam parte.

Diferentes vicissitudes, que não espantam na longa duração de vida desses organismos da administração colonial portuguesa central e dos respetivos arquivos, afetaram-nos de formas nem sempre totalmente apuradas. Acidentes naturais, guerras, reorganizações administrativas, mudanças de responsáveis políticos, transferências de serviços e cartórios, retenção involuntária ou indevida de documentos e escassez de pessoal qualificado repercutiram-se nesses arquivos, por vezes negativamente. 
A cessação de funções ou o falecimento de quem as exercia a vários níveis, mas nomeadamente entre escrivães produtores e custodiadores de cartórios, nem sempre era acompanhada da inventariação e devolução obrigatória da documentação do real serviço, ou seja, do Estado.

Relativamente à Secretaria de Estado da Marinha e dos Domínios Ultramarinos sabe-se, por exemplo, que à morte do rei $\mathrm{D}$. João $\mathrm{V}$, em 31 de julho de 1750, o arquivo se encontrava numa tal confusão, nas palavras do recém-nomeado secretário de Estado Diogo Mendonça Corte Real filho, que até uma carta para a rainha de Espanha ficou esquecida e não foi expedida pelo Correio em devido tempo (Korobtchenko, 2011, p.39, n.110).

Já depois do terramoto de 1755, o arquivo do Conselho Ultramarino, por seu turno, terá ido para o palacete do conselheiro Alexandre de Metelo de Souza e Meneses, no Campo do Curral, hoje Campo Santana ou Campo dos Mártires da Pátria (Miranda, 2009). Esteve às portas de Santo Antão, no Palácio da Anunciada, nas casas dos Lavre, secretários do Conselho, desorganizado, até 1796, ano em que foi para Rua do Ouro perto do Terreiro do Paço (Bicalho, 2011, p.308, 310, 311).

A confusão de papéis e livros foi igualmente assinalada em arquivos da administração colonial da capitania de São Paulo, por exemplo pelo governador D. Luís António de Sousa, em 1773, a propósito da Junta da Real Fazenda e da Provedoria antiga, como a designou. D. Luís referiu ainda a dificuldade de encontrar na capitania pessoal preparado, caso dos amanuenses e contabilistas. $^{3}$

Essa dificuldade estendia-se a cargos tão relevantes para a constituição, organização e funcionamento dos arquivos, quanto o de secretário do Governo da Capitania e até, por vezes, ao de secretário do Conselho Ultramarino ou de oficial-mor da Secretaria de Estado. As referências a candidaturas, a perfis exigíveis e à necessidade de remunerar adequadamente são várias na documentação dessas instituições, como bem estudou Caio Boschi nomeadamente quanto aos secretários do governo da capitania de Minas Gerais (Boschi, 2011). O Conselho Ultramarino, por exemplo, em 1711, mencionava por um lado a ausência de resposta ao edital do concurso para o cargo de secretário da capitania de São Paulo e Minas, afixado durante largo tempo nas portas do Conselho e em outros lugares e, por outro, considerava que os oficiais da Secretaria de Estado seriam os de maior préstimo e com melhor conhecimento dos negócios, mas deveriam ganhar mais. ${ }^{4}$

Em $1^{\circ}$ de novembro de 1755 o terramoto provocou uma imensa destruição no Paço Real no Terreiro do Paço, onde habitualmente funcionavam as 
Secretarias de Estado e o Conselho, este junto da Casa da Índia e do Conselho da Fazenda. Não tendo sido o terramoto o responsável por todas as falhas na documentação do Conselho Ultramarino e da Secretaria de Estado da Marinha e dos Domínios Ultramarinos, o incêndio que se lhe seguiu fez desaparecer alguns livros, parte dos quais anos depois reformados, isto é, reconstituídos por cópia, como aconteceu com o livro das posses do Conselho Ultramarino datado de 1642-1761 (Caetano, 1968, p.53).

Mais tarde, as Guerras Napoleónicas e a mudança da Corte portuguesa para o Brasil, em 1807-1808, a ocupação francesa do Reino, a reação militar anglo-lusa, a continuada presença britânica, a Revolução de 1820 e o regresso da Corte a Lisboa em 1821 marcaram a trajetória destes e de outros arquivos. Por um lado, levaram a uma bem-sucedida operação transatlântica de transferência de arquivos (e de bibliotecas) em ambas as direções, pesem embora vários percalços. Por outro, no Reino, a militarização do dia a dia suscitou a preocupação de arquivistas, no caso o guarda-livros do Conselho Ultramarino, quanto a riscos de incêndio que a proximidade de depósitos militares apresentava. ${ }^{5}$ Paralelamente, verificaram-se alterações nos circuitos de governação, com reflexo na organização dos arquivos do Conselho Ultramarino e da Secretaria de Estado (Martins, 2007, p.63, 94, 121-123, 126, 200, 313, 341). Além disso, regressado o rei a Lisboa, temos notícia, em 1822, de mudança de instalações do Conselho, incluindo o cartório ${ }^{6}$ e, alguns anos depois, em 1826, nova preocupação com a situação do edifício do Pátio das Vacas, a Belém, não longe do Convento dos Jerónimos, onde se encontrava o cartório daquela Secretaria de Estado. ${ }^{7}$

A guerra civil em Portugal entre partidários de D. Pedro, o primeiro imperador do Brasil e futuro Pedro IV de Portugal, e o irmão D. Miguel, também ocasionou transferências de arquivos, assinalando-se o do Conselho Ultramarino, logo em 1828, pelos miguelistas.

Já em 1842, na sequência da extinção do Conselho Ultramarino em 1833 que determinou a transferência do arquivo para a Secretaria de Estado da Marinha e Ultramar, esse arquivo foi objeto de uma proposta de esboço de organização por Filipe Roberto da Silva Stockler, anterior oficial papelista e do assentamento do referido Conselho. No caso dos documentos avulsos, propunha a organização por tipo de documento - Avisos, Consultas, Decretos, Lembretes, Papéis de Serviço, Requerimentos, a que acresceria uma Miscelânea - e por ano em que tinham sido processados. Realçava ainda a importância, para a utilização do arquivo, dos Livros da Porta relativos aos Despachos do Conselho e dos Livros de Registo, entre os quais de Cartas, Alvarás, Provisões 
e Ordens ${ }^{8}$ - registados num mesmo livro ou em livros distintos, dependendo possivelmente do volume de documentos. Por volta de 1856, o conjunto dos livros do Conselho Ultramarino que se encontravam na Secretaria de Estado foi precisamente objeto de uma relação, em que também se mencionava o seu bom estado de conservação. ${ }^{9}$

Décadas depois, em 1889, a documentação dos arquivos do Conselho Ultramarino e da Secretaria de Estado dos Negócios da Marinha e dos Domínios Ultramarinos, já muito misturada, de acordo com Rafael Eduardo Azevedo de Basto, conservador do Arquivo Nacional da Torre do Tombo, que dela fez uma relação, foi transferida do Arsenal, ao Terreiro do Paço, para a Biblioteca Nacional, ao Chiado. Na Biblioteca Nacional essa documentação formou em 1901 a base da Seç̧ão do Arquivo de Marinha e Ultramar, designada Secção de Marinha e Ultramar em 1918-1919 (Miranda, 2009; Fitzler, 1928; Pereira, 1902).

Deve ainda referir-se que em 1894 cerca de uma dezena de livros do arquivo do Conselho Ultramarino, talvez oriundos primitivamente do Conselho da Fazenda, foi transferida do chamado Arquivo dos Bens Próprios Nacionais (constituído no contexto da extinção em 1834 das ordens religiosas e da venda dos respetivos bens) para o Arquivo Nacional da Torre do Tombo, onde se encontram.

Na Biblioteca Nacional iniciou-se a organização da documentação avulsa do Conselho Ultramarino, compreendendo também os avulsos da Secretaria de Estado dos Negócios da Marinha e dos Domínios Ultramarinos, em séries geográficas, para elaboração de instrumentos de acesso, caso dos catálogos da Madeira e Porto Santo, e da Bahia e do Rio de Janeiro, logo a seguir, por acordo com o Brasil, todos da autoria de Castro e Almeida (Almeida, 1907-1909; Almeida, 1913-1951).

Em 1931, com a criação do Arquivo Histórico Ultramarino (AHU), então chamado Colonial, essa documentação foi transferida para o Palácio da Ega, permanecendo ainda hoje alguma residual na Biblioteca Nacional de Portugal, nos Reservados (Códices e Manuscritos Avulsos), no Fundo Geral e na Cartografia. A proveniência arquivística dessa documentação está por estabelecer sistematicamente de forma individualizada. ${ }^{10}$ Mas, em alguns casos, foi possível fazê-lo, associando documentos separados entre coleções e/ou entre entidades detentoras, em especial os documentos textuais principais e os respetivos anexos. ${ }^{11}$

Já no AHU, foi continuada a organização geográfica dos avulsos, embora em 1950, Alberto Iria, director entre 1946 e 1975, tenha sido claro quanto à 
preferência em respeitar organizações anteriores que existiriam, pelo menos relativamente a grupos de documentação, em alguns períodos, por temas mas sobretudo por actos e tipologias: correspondência entrada e saída, avisos, ofícios, cartas de sesmaria, consultas, requerimentos, contratos reais, papéis de serviço, provisões, portarias, decretos etc. Organizações estas combinadas com uma ordenação cronológica e por vezes geográfica e, acrescento, com ordenação alfabética pelo primeiro nome, por exemplo no caso dos requerimentos. Mas Iria, prudente em não ignorar eventuais organizações anteriores, foi ao mesmo tempo pragmático quanto à inviabilidade de voltar atrás na organização geográfica dos avulsos (Iria, 1950). Foi essa aliás a situação com a qual o projeto Resgate - Barão do Rio Branco deparou no tratamento arquivístico da documentação avulsa relacionada com o Brasil, na década de 1990.

Neste quadro, convém notar o quão distantes essas séries geográficas poderão estar em relação a eventuais sistemas ou, mais modestamente, formas de organização de conjuntos desses documentos. Esta distância, aliada à variabilidade do âmbito geográfico das estruturas orgânicas de governo e da administração colonial, condiciona a atividade de organização e de descrição documental. No caso das séries de documentos avulsos do Brasil, por maioria de razão, considerando a dimensão da documentação e devido às várias alterações verificadas na configuração administrativa das capitanias durante cerca de 180 anos. A decisão de associar um documento a uma série geográfica do Brasil e não a outra, nem sempre foi evidente, e os critérios por vezes variaram. Importa sobretudo ter a consciência de que as ligações entre documentos das diversas séries são muito maiores do que à partida se possa pensar, e que informação relevante sobre determinado acontecimento ocorrido numa capitania pode encontrar-se também em outra série que não a da própria capitania. $\mathrm{O}$ conhecimento sobre esses aspetos da história dos próprios arquivos pode ser dispensável em usos como o da reapropriação artística de documentos, mas contribui, em geral, para a aproximação à verdade, na utilização da informação neles contida, nomeadamente por quem faz investigação histórica.

Procuremos concretizar um pouco, observando, por exemplo, o que se passa com a documentação e os conteúdos informativos do fundo de arquivo do Conselho Ultramarino relativamente a São Paulo.

Como sucede em todos os arquivos de matriz ocidental baseados na escrita e especialmente em suporte papel, os do fundo do Conselho Ultramarino 
agregam em primeiro lugar registos e outros instrumentos de controlo da entrada, saída e circulação interna da documentação emitida e recebida pelo Conselho Ultramarino e pela Secretaria de Estado da Marinha e dos Domínios Ultramarinos e ainda, em reduzido número, pelo Conselho da Fazenda, antes de 1642. Tais instrumentos, conhecidos por códices, foram encadernados de forma diferente consoante pertenciam ao arquivo do Conselho Ultramarino ou ao da Secretaria de Estado. Grosso modo, os primeiros têm encadernação inteira em carneira, com decoração por ferros a seco e nas pastas as armas reais, por vezes a esfera armilar e a cruz de Cristo, tendo as lombadas cinco ou seis nervuras. Os rótulos, em carneira pintada, são decorados a ouro ou em papel, com o número, título ou conteúdo e as datas extremas do livro. Os da Secretaria de Estado apresentam encadernação inteira de pergaminho, lombadas com duas nervuras, cobertas de carneira vermelha com tiras de camurça branca. $\mathrm{O}$ título ou conteúdo e as respetivas datas extremas estão escritos a tinta sobre o pergaminho (Martinheira, 2001).

A recente descrição desses livros, e sobretudo a identificação do organismo a cujo arquivo pertenciam, até por essa diferença óbvia nas características externas, a que em muitos casos se acrescentam termos de abertura e encerramento e numeração na origem, foi naturalmente mais fácil do que a da documentação avulsa.

Os registos foram com frequência feitos por cópia integral do documento, embora raramente compreendendo os anexos, em muitos casos referenciados, pelo menos genericamente. Anexos relevantes, como listas de espécies botânicas, surgem copiados na segunda metade do século XVIII. Os livros têm, por vezes, índices próprios, cuja organização variou: frequentemente pelo primeiro nome do indivíduo ou da entidade que iniciou o procedimento administrativo, nem sempre bem ordenado; outras vezes mais um catálogo do que um índice, puramente pela ordem de registo, sumariando o conteúdo do documento em causa.

Não existindo para todo o período de funcionamento dos organismos, seja por nunca terem sido criados, seja por não terem chegado até hoje, os livros de registo que subsistem funcionam enquanto chaves para aceder a outros documentos e a mais informação, como bem sabia o oficial papelista Stockler. Por um lado, esses livros apresentam conteúdos informativos nem sempre presentes na documentação avulsa do Conselho Ultramarino; por outro, mesmo quando são constituídos por resumos ou cópias de documentos avulsos que estão neste ou em outros fundos de arquivo, os registos podem acrescentar informação ligada à tramitação administrativa e aos circuitos de 
decisão. Em certos casos, permitem identificar os agentes e entidades que intervêm na produção dos documentos e reconstituir procedimentos de despacho e os meandros do poder, em diferentes níveis e formas. Assim sucede com os livros que registam, muitas vezes por cópia, os documentos enviados para o governo da capitania de São Paulo, e parte dos recebidos, seja deste governo seja de outras entidades, mas relacionados com esta capitania.

Ainda relativamente a esses livros, deve referir-se que, tanto no caso do Conselho Ultramarino quanto no da Secretaria de Estado da Marinha e Domínios Ultramarinos, só em relação a certo tipo de documentos e/ou em determinado período cronológico, associado geralmente a maior volume documental, é que se produziram livros segundo áreas geográfico-administrativas. No Conselho Ultramarino, para a capitania de São Paulo, é o caso dos dois volumes de registo de cartas régias, provisões e outras ordens entre 1726 e 1806 e de outros dois volumes de registo de consultas, datados de 1726 a $1809 . \mathrm{Na}$ Secretaria de Estado da Marinha e dos Domínios Ultramarinos, identificam-se mais outros dois livros de registo de ordens régias e avisos específicos para São Paulo datados entre 1765, o ano de início da governação de D. Luís António de Sousa, posteriormente Morgado de Mateus, e 1821, ano do regresso do rei D. João VI a Portugal.

Grande parte dos livros de registo foram criados para recuperar os documentos de acordo com as tipologias e também os assuntos, a que se aliavam os nomes de pessoas e entidades e uma referência cronológica. Falamos, por exemplo, dos numerosos livros de registo das consultas, em particular das consultas de partes, que constituem 45 volumes entre 1620 e 1833. A sua informação podia ser cruzada com a dos livros de porta, de que se conhecem 25 no Conselho Ultramarino (1731-1832) e 55 na Secretaria de Estado (1796-1835) e onde se registava a data de entrada e do despacho de requerimentos que davam frequentemente origem àquelas consultas, bem como o nome do requerente ou procurador. Aí se registava igualmente a devolução de documentos, até porque os anexos dos requerimentos, em geral certidões que eram pagas, podiam ser reutilizados.

Os sistemas de funcionamento de ambos os organismos tiveram certamente alguma relação com os modos como foram sendo organizados os respetivos arquivos, mas não se apurou ainda até que ponto assim aconteceu. $\mathrm{O}$ agendamento do despacho variava entre a natureza dos assuntos e a área geográfico-administrativa a que diziam respeito, além dos correspondentes grau de urgência e relevância. Logo na criação do Conselho Ultramarino, o Regimento, no art. $10^{\circ}$, estipulava estes últimos como princípios genéricos: 
"deve começar-se pelos mais importantes e que mais brevidade pedirem". Três anos depois, em 1645, atribuíam-se as quintas e as sextas-feiras aos negócios do Brasil, os outros três dias da semana aos da Índia, e os sábados aos da Guiné, Cabo Verde e outras "conquistas". Mas logo no ano a seguir, consagrava-se uma manhã por semana ao despacho de mercês, dia esse que em 1663 era a quinta-feira (Caetano, 1968, p.48-49, 121). Muitos anos mais tarde, em 1805, esse dia era por sua vez consagrado ao despacho dos particulares pelo secretário de Estado dos Negócios da Marinha e dos Domínios Ultramarinos - tal como pelo dos Negócios do Reino (Almeida, 2008, p.344, n.904).

A organização, ou melhor as organizações que a documentação avulsa foi assumindo nos arquivos dos dois organismos da administração colonial central são, como já se sugeriu, muito mais difíceis de reconstituir, e a distinção entre proveniências dos documentos nem sempre é evidente, mesmo recorrendo aos livros de registo, no caso de subsistirem. A opção pela constituição de séries geográficas, já se afirmou, terá sido a possível e a que porventura viabilizou um acesso mais rápido aos conteúdos informativos dos documentos. Mas é preciso ter bem presentes as diversas configurações territoriais e de dependência administrativa da capitania de S. Paulo (como no caso de outras capitanias) para se ter uma visão mais correta da possível localização de documentos e de informação a ela respeitantes, no fundo de arquivo do Conselho Ultramarino.

Recordemos, muito rapidamente, os principais marcos dessas reconfigurações da administração colonial de espaços brasileiros e que se tornam mais nítidas a partir do abandono da figura dos donatários, com pouca expressão na segunda metade do século XVII. A Capitania de São Paulo e Minas do Ouro foi criada em 9 de novembro de 1709 após aquisição, pela Coroa, da Capitania de São Vicente. Empossado em São Paulo em 12 de junho de 1710, o primeiro governador, António de Albuquerque Coelho, deslocou-se para o Ribeirão do Carmo, residindo os seus sucessores em Minas Gerais (Silva, 2009). Até constituir, em 2 de dezembro de 1720, nova capitania, Minas Gerais foi o objeto principal da governação da capitania de São Paulo, e a documentação desta última encontrava-se no governo de Minas.

Já no governo de Rodrigo César Meneses, entre 1721 e 1728, foi necessário recolher documentação, em especial junto do Rio de Janeiro, e o rei ordenar ao governador de Minas Gerais o envio de cópias de documentos de interesse para São Paulo. Mas o inverso também acontecia. Em abril de 1726, o ouvidor-geral de Paranaguá escreveu ao rei D. João V, dizendo que requerera ao ouvidor-geral de São Paulo que determinasse a separação dos livros pertencentes à Ouvidoria de Paranaguá, uma vez que ela fora desanexada da de São Paulo. 
Em 1748 São Paulo foi agregado à capitania do Rio de Janeiro, o que, no ano seguinte, se traduziu na transferência de documentação, através de para esta última cidade. Traduziu-se também, a partir dessa data, na produção e acumulação de documentos relativos a São Paulo na capitania do Rio de Janeiro, em articulação com o Conselho Ultramarino e com a Secretaria de Estado da Marinha e dos Domínios Ultramarinos em Lisboa.

Em 1765, São Paulo voltou a ser erigida a capitania, perdendo, no entanto, áreas para as capitanias de Goiás e do Mato Grosso. Ficava com o território dos atuais estados de São Paulo e do Paraná e parte do de Santa Catarina. Durante todo esse período, e até à independência do Brasil, verificaram-se ainda outras mudanças menos significativas no âmbito territorial do governo da capitania de São Paulo, como foi o caso, por exemplo, da integração das Lages na capitania de Santa Catarina em 1820 (Silva, 2009).

Tais mudanças administrativas tiveram reflexo não apenas nos arquivos das secretarias dos governos das capitanias nos territórios brasileiros, mas também no do Conselho Ultramarino e, a partir de 1736 e sobretudo de meados do século XVIII, no da Secretaria de Estado da Marinha e dos Domínios Ultramarinos.

No caso da documentação avulsa, mesmo quando na atividade de descrição documental se esteve ciente de todas essas alterações, a aplicação do critério geográfico na organização de séries apresentou dificuldades. Simultaneamente, esse intrincado percurso leva a que a pesquisa de informação relativa à capitania de São Paulo não se deva cingir à respetiva série documental. Esta série, aliás, dispõe ela própria de dois instrumentos de acesso, um resultante do chamado catálogo Mendes Gouveia, revisto (Arruda et al., 2000), e outro elaborado de raiz no âmbito do Projeto Resgate (Arruda et al., 2002). Convém assim estender a pesquisa sobre São Paulo à série de avulsos do Rio de Janeiro, e, sobretudo em determinados períodos, e para determinados assuntos ou pessoas, a mais séries do Brasil, incluindo a do Brasil-Geral, e até a séries relativas a outros espaços da administração ultramarina portuguesa. Lembremo-nos de que a governação ultramarina portuguesa, moldando-se de acordo com as realidades mutáveis entre o Atlântico, o Índico e os Mares da China, considerava-as, com maior ou menor sucesso, de modo global e sempre, naturalmente, em função dos seus interesses, também eles variáveis e por vezes contraditórios. Questões como o tráfico de escravos, a procura e a transformação de recursos naturais, ou a circulação de produtos, ligaram profundamente espaços e comunidades brasileiras, incluindo a capitania de São Paulo, a espaços e comunidades africanas, nomeadamente da costa atlântica. ${ }^{12}$ Tanto a série documental de São Paulo 
quanto as de Angola, de Cabo Verde, da Guiné, de São Tomé e Príncipe, do Ultramar e até a do Reino, registam esta e outras experiências comuns. Outras questões, como a concessão de sesmarias, cujos documentos, além do valor histórico, readquiriram valor legal, não se confinam às séries geográficas dos avulsos. Por outro lado, fenómenos como a mobilidade de pessoas, verificada entre múltiplos postos e cargos nas várias áreas coloniais portuguesas, estão transversalmente documentados no fundo de arquivo do Conselho Ultramarino. É por isso necessário perseguir essas informações pelas diferentes séries de avulsos e de livros de registo e relacioná-las entre si.

Com a ida da Corte portuguesa para o Rio de Janeiro em 1808, que, para a historiografia brasileira, marca o fim do período do Brasil Colónia, a relação da capitania de São Paulo passou a ser feita sobretudo com o Governo central sediado naquela cidade. O Conselho Ultramarino viu esvaziadas praticamente as suas competências, que foram distribuídas pela Mesa de Consciência e Ordens e pelo Desembargo do Paço, recriados no Brasil, e ainda pelo Conselho Supremo Militar aí estabelecido, ficando as funções de expediente asseguradas em Lisboa, onde funcionou até 1820 um Conselho de Governadores do Reino, excetuando uma breve interrupção no período de ocupação pelo exército de Napoleão. A Secretaria de Estado dos Negócios da Marinha e dos Domínios Ultramarinos reassumiu nos trópicos brasileiros as funções que já detinha, estabelecendo uma articulação com Lisboa por intermédio do Governador do Reino encarregado dos assuntos da Marinha e Ultramar. Mas os negócios do Brasil, incluindo os da capitania de São Paulo, ficaram integrados na Secretaria de Estado do Negócios do Reino, que passou a designar-se dos Negócios do Brasil e, mais tarde, do Reino do Brasil. Ou seja, para o período entre 1808 e a independência do Brasil e anos imediatos, relativamente à capitania de São Paulo, como quanto a outras capitanias brasileiras, justifica-se consultar, além do fundo do Conselho Ultramarino, a documentação da Mesa de Consciência e Ordens e do Desembargo do Paço, bem como a da Secretaria de Estado dos Negócios do Brasil existentes no Arquivo Nacional e ainda na Biblioteca Nacional do Brasil, no Rio de Janeiro (Martins, 2007, p.333-339).

As redes informativas, geograficamente amplas, tecidas pela administração ultramarina portuguesa, deixaram registos de longa duração em arquivos comuns ao Brasil e a Portugal e ainda a outros países e comunidades. Tais arquivos de organismos centralizados em Lisboa, especificamente do Conselho 
Ultramarino e da Secretaria de Estado dos Negócios da Marinha e dos Domínios Ultramarinos, têm histórias próprias, singulares, cuja reconstrução permitirá usos mais criteriosos da informação que contêm. Com esta breve abordagem pretendeu-se alertar para a vantagem do conhecimento sobre o que está por detrás da documentação produzida por aqueles arquivos, na forma como hoje se apresenta e que nunca é inócua. Vantagem que se torna uma exigência no ofício de historiador.

\section{REFERÊNCIAS}

ALMEIDA, Eduardo de Castro e (Org.) Archivo de Marinha e Ultramar, inventário: Madeira e Porto Santo. Coimbra: Biblioteca Nacional de Lisboa, 1907-1909. 2v. (v.1: 1613-1819; v.2: 1820-1833).

. Inventário dos documentos relativos ao Brasil existentes no Archivo de Marinha e Ultramar de Lisboa. Rio de Janeiro: Biblioteca Nacional, 1913-1951, 9v. (v.15: Bahia; v.6-8: Rio de Janeiro).

ALMEIDA, Joana Estorninho de. A cultura burocrática ministerial: repartições, empregados e quotidiano das secretarias de estado na primeira metade do século XIX. Tese (Doutoramento) - Instituto das Ciências Sociais, Universidade de Lisboa. Lisboa, 2008. Disponível em: http://repositorio.ul.pt/handle/10451/314; acesso em: 20 jan. 2018.

ARRUDA, José Jobson de A. (Coord. geral); BELLOTTO, Heloísa L.; REIS, Gilson

Sérgio M. (Org.) Documentos Manuscritos Avulsos da Capitania de São Paulo (1644-1830): Catálogo 1. Bauru, SP: Edusc; São Paulo: Fapesp; Imesp, 2000.

ARRUDA, José Jobson de A. (Coord. geral); BELLOTTO, Heloísa L.; REIS, Gilson Sérgio M. (Org.) Documentos Manuscritos Avulsos da Capitania de São Paulo (1618-1823): Catálogo 2 - Mendes Gouveia. Bauru, SP: Edusc; São Paulo: Fapesp; Imesp, 2002.

BAIÃO, António. Uma pequena achega para a história da arquivologia portuguesa. Anais das Bibliotecas e Arquivos, Lisboa, v.14, n.55-56, p.10-12, 1939.

BETHENCOURT, Francisco. A América Portuguesa. In: BETHENCOURT, Francisco; CHAUDHURI, Kirti (Dir.) História da Expansão Portuguesa. v.3: O Brasil na Balança do Império (1697-1808). Lisboa: Círculo de Leitores, 1998a. p.228-249.

. O Estado da Índia. In: BETHENCOURT, Francisco; CHAUDHURI, Kirti

(Dir.). História da Expansão Portuguesa. v.3: O Brasil na Balança do Império (16971808). Lisboa: Círculo de Leitores, 1998b. p.250-269.

BICALHO, Maria Fernanda. Ascensão e queda dos Lopes de Lavre: secretários do Conselho Ultramarino. In: MONTEIRO, Rodrigo B.; FEITLER, Bruno; CALAINHO, Daniela B.; FLORES, Jorge (Org.) Raízes do Privilégio: mobilidade social no 
mundo ibérico do Antigo Regime. Rio de Janeiro: Civilização Brasileira, 2011. p.283-304.

BOSCHI, Caio C. O Brasil-Colônia nos arquivos históricos de Portugal: roteiro sumário. São Paulo: Alameda, 2011a.

Os secretários do governo na capitania de Minas Gerais. In: Exercícios de pesquisa histórica. Belo Horizonte: PUC-Minas, 2011b. p.59-100.

BOXER, Charles R. O Império Colonial Português. Lisboa: Ed. 70, 1981. (Trad. de: The Portuguese seaborne empire 1415-1825. New York: Alfred Knopf, 1969).

CAETANO, Marcelo. O Conselho Ultramarino: esboço da sua história. Lisboa: Agência-Geral do Ultramar, 1968.

CHAUDHURI, Kirti. O Império na economia mundial. In: BETHENCOURT, Francisco; CHAUDHURI, Kirti (Dir.) História da Expansão Portuguesa. v.2: Do Índico ao Atlântico (1570-1697). Lisboa: Círculo de Leitores, 1998. p.121-137.

FITZLER, M. A. Hedwig; ENNES, Ernesto. A Secção Ultramarina da Biblioteca Nacional: Inventários. Lisboa: Oficinas Gráficas da Biblioteca Nacional, 1928.

GARCIA, João (Ed. lit.) A nova Lusitânia: imagens cartográficas do Brasil nas colecções da Biblioteca Nacional (1700-1822): catálogo. Lisboa: Comissão Nacional para as Comemorações dos Descobrimentos Portugueses, 2001.

IRIA, Alberto. A constituição do Arquivo: proveniência e importância dos seus fundos. Boletim do Arquivo Histórico Colonial, Lisboa: Arquivo Histórico Colonial, v.1, p.55-66, 1950.

KOROBTCHENKO, Júlia P. A Secretaria de Estado dos Negócios Estrangeiros e da Guerra: a instituição, os instrumentos e os homens (1736-1756). Dissertação (Mestrado em História Moderna) - Universidade de Lisboa. Lisboa, 2011. Disponível em: http://repositorio.ul.pt/bitstream/10451/6809/1/ulfl107713_tm.pdf; acesso em: 20 jan. 2018.

MARTINHEIRA, José Joaquim S. (Org.) Catálogo dos Códices do Fundo do Conselho Ultramarino Relativos ao Brasil existentes no Arquivo Histórico Ultramarino. Lisboa: Fundação Calouste Gulbenkian, 2001.

MARTINS, Ana Canas D. Governação e Arquivos: D. João VI no Brasil. Lisboa: ANTT, 2007.

MIRANDA, Tiago C. P. dos Reis. A organicidade dos fundos de Antigo Regime: o "público" e o "privado" nas coleções do Conselho Ultramarino (séc. XVII-XIX). In: JORNADA SOBRE ARQUIVOS DE FAMIILIA: ÉPOCAS MEDIEVAL E MODERNA, 20 maio 2009, Lisboa. Anais... Lisboa: FCSH-UNL, 2009.

PEREIRA, Gabriel. Biblioteca Nacional de Lisboa: o Archivo Ultramarino. Lisboa: Typographia do Dia, 1902.

RUSSELL-WOOD, Anthony John R. A emigração: fluxos e destinos. In: BETHENCOURT, Francisco; CHAUDHURI, Kirti (Dir.) História da Expansão Portuguesa. 
v.3: O Brasil na Balança do Império (1697-1808). Lisboa: Círculo de Leitores, 1998a. p.158-168.

RUSSELL-WOOD, Anthony John R. Governantes e agentes. In: BETHENCOURT, Francisco; CHAUDHURI, Kirti (Dir.) História da Expansão Portuguesa. v.3: O Brasil na Balança do Império (1697-1808). Lisboa: Círculo de Leitores, 1998 b. p.169-192.

SILVA, Maria Beatriz Nizza da (Org.) História de São Paulo colonial. São Paulo: Ed. Unesp, 2009.

\section{NOTAS}

${ }^{1}$ Agradeço as sugestões feitas pelos avaliadores da Revista Brasileira de História.

${ }^{2}$ Ver, por exemplo, Documentos da Fazenda de Luanda com despacho do governador André Vidal de Negreiros, Luanda, 28 de maio de 1663 - 16 de agosto de 1668. AHU, CU, Angola, Cx. 7, D. 830 e Conta No 632 de José Caetano da I (?) para Baltazar Manuel Pereira do Lago Governador Interino dos Rios de Sena, Vila de Sena, 20 de fevereiro de 1761. AHU, CU, Moçambique, Cx. 56, D. 44. Agradeço a José Sintra Martinheira a referência dos documentos.

${ }^{3}$ 1773, Julho, 23, São Paulo, carta do (governador e capitão-general da capitania de São Paulo), D. Luís Antônio de Sousa (Botelho Mourão) para (o secretário de Estado dos Negócios da Marinha e Domínios Ultramarinos) Martinho de Melo e Castro. AHU, CU, 02301, Cx. 29, D. 2634

${ }^{4}$ 1711, Dezembro, 11, Lisboa, consulta (minuta.) do Conselho Ultramarino, sobre o provimento do

ofício de secretário da capitania de São Paulo e Minas (de Ouro), para o qual, cumprindo as ordens de (D. João V), se puseram editais. AHU, CU, 023-01, Cx. 1, D. 101.

${ }^{5}$ [ant. 1812, Agosto, 25, Lisboa], requerimento do guarda-livros do Conselho Ultramarino, José Maria de Sousa Duarte Coutinho, ao príncipe regente [D. João]. AHU, CU, 089, Cx. 16, D. 1466.

${ }^{6}$ 1822, Janeiro, 15 - Setembro, 10, Queluz, portarias (9) do secretário de Estado dos Negócios do Reino, Filipe Ferreira de Araújo e Castro, ao Conselho Ultramarino. AHU, CU, Reino, Cx. 355, pasta 32.

7 1826, Agosto, 17 - 29, [Lisboa], aviso e ofício do [secretário de Estado da Guerra], João Carlos de Saldanha de Oliveira Braun, ao ministro e [secretário de Estado dos Negócios da Marinha e Ultramar], Manuel Inácio da Costa Quintela. AHU, CU, Reino, Cx. 383, pasta 72.

${ }^{8}$ Sistema para arquivar os papéis do extinto Conselho Ultramarino submetido à aprovação do Ilmo. Snr. António Pedro de Carvalho oficial maior da Secretaria de Estado dos negócios da Marinha e Ultramar em 28 de Novembro de 1842. AHU, SEMU, s/ $\mathrm{n}^{\circ}$. 
${ }^{9}$ Relação dos Livros que pertenciam ao extinto Conselho Ultramarino e que hoje se acham na Secretaria de Estado dos Negócios da Marinha e Ultramar, c. 1856. AHU, SEMU, s/nº.

${ }^{10}$ Para uma ideia sobre este tipo de documentação na Biblioteca Nacional de Portugal, embora sem se referir especificamente à proveniência arquivística, ver BOSCHI, 2011a, p.209-217, e instrumentos de acesso e bibliografia mencionados.

${ }^{11}$ Caso, por exemplo, de STURM, Filipe, fl. 1750-1770. Planta da casa de rezidencia do R. P. Vizitador, e Vigario desta Villa de Barcellos. [Post. 1755]. Referenciada a documentação do AHU, CU, Rio Negro (GARCIA, 2001, p.267-268). Este e outros exemplos (GARCIA, 2001, p.32, 194-196, 268-269) advêm de investigação envolvendo, entre outras instituições, a BNP e o IICT, e de que resultou a mencionada publicação. Agradeço a Maria Joaquina Feijão a referência.

${ }^{12}$ Ver, nomeadamente sobre várias das “Configurações do Império" colonial português, os que o governavam e administravam, as ligações entre diferentes espaços e as atividades económicas, por exemplo, BETHENCOURT, 1998a; 1998b; RUSSELL-WOOD, 1998a; 1998b; CHAUDHURI, 1998 e, anteriormente, BOXER, 1981[1969], cap.6-8.

Artigo recebido em 7 de fevereiro de 2018.

Aprovado em 30 de maio de 2018.

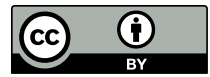

